\title{
Norma Social Violenta: Um Estudo da Representação Social da Violência em Adolescentes
}

\author{
Violent Social Norms: A Study on the Symbolic Elaboration of Violence in Adolescents \\ Silvia Pereira Guimarães** \& Pedro Humberto Faria Campos \\ Universidade Católica de Goiás, Goiânia, Brasil
}

\begin{abstract}
Resumo
Este trabalho buscou abordar a violência a partir dos adolescentes, explorando o campo consensual da representação social e identificando alguns elementos que atuam como orientadores e justificadores da ação violenta. A noção de violência remete a um abuso, um excesso que se verifica no interior das relações de poder. Atualmente este fenômeno é marcado por uma "tendência à banalização" e pelo grande envolvimento de jovens. Nesse sentido, o estudo foi realizado com adolescentes estudantes de escolas públicas de Goiânia através de entrevistas semi-diretivas submetidas a uma análise utilizando-se o software Analyse Lexicale par Contexte d'un Ensemble de Segments de Texte (ALCESTE). Esses dados reforçam a hipótese de uma tendência a banalização da violência e apresenta um discurso em que esta é reconhecida em situações marcadas pela agressão física. A violência é vista como algo "comum", sendo até mesmo "esperada” em certos contextos como parte de uma norma social.
\end{abstract}

Palavras-chave: Violência; adolescência; representações sociais.

\begin{abstract}
The present work approaches teenage violence, exploring the consensual field of social representation and identifying some elements that act as guiders and justifiers of violent action. The notion of violence leads to an abuse or an excess that is verified in the relations of power. Currently this phenomenon is characterized by a certain "trend to banalize" and by an ample involvement of youngsters. The study was thus carried out with adolescent students from public schools in Goiânia by means of half-directive interviews that were submitted to an analysis using the software Analyse Lexicale par Contexte d'un Ensemble de Segments de Texte (ALCESTE). The data strengthens the hypothesis of the "trend to banalize" violence and presents a discourse in which this is recognized in situations of physical aggression. Violence is seen as something ordinary and even expected in certain contexts as part of a social norm.
\end{abstract}

Keywords: Violence; adolescents; social representations.

Atualmente a violência, em suas múltiplas formas, está presente nos mais diferentes espaços da sociedade brasileira, chegando a ocupar lugar de grande destaque na vida cotidiana das pessoas. Um dos aspectos alarmantes apontados em pesquisas recentes diz respeito ao crescente envolvimento de jovens, em especial de adolescentes, com a violência, tanto no papel de vítimas quanto no de agressores. Além disso, o aumento da "gravidade" das práticas violentas e a constatação de que estes elementos têm sido gradativamente incorporados ao modo de vida dos jovens são dados de grande relevância e que suscitam uma série de questionamentos (Abramovay, Waiselfisz, Andrade \& Rua, 2004; Adorno, Bordini \& Lima, 1999; Pinheiro \& Almeida, 2003).

Essa percepção da proximidade existente entre a violência cotidiana e a adolescência preocupa, inquieta e, ao mesmo tempo, motiva-nos a mergulhar nesta realidade.

\footnotetext{
* Endereço para correspondência: Rua C-167, Quadra 376, Lote 13, Jardim América, Goiânia, Goiás, 74255-100. Fone: (62) 3286-1581 e (62) 9637-6799. E-mail: silviapguimaraes@yahoo.com.br
}

Procuramos, assim, fugir das análises massificadas, como impõem os dados estatísticos e a mídia sensacionalista, buscando compreender como os adolescentes percebem essa realidade violenta que os envolve e orienta suas ações.

Ao considerar a adolescência como um fenômeno cultural marcado por um período psicossociológico bastante específico - destituído de foco exclusivo nos aspectos biológicos/pubertários - seus elementos simbólicos e sua dinâmica interna adquirem grande importância. Estes elementos do "processo adolescente" encontram expressão na realidade social e vão ao encontro da violência.

A violência, enquanto fenômeno social complexo que suscita representações, deve ser compreendida a partir das condutas e práticas humanas que lhes dão suporte, em conjunto com os sistemas simbólicos que lhes conferem sentido. Cada grupo social elabora a partir de suas ações (práticas sociais), um sistema de representações ou um "sistema representacional' para lidar com situações sociais complexas, que funciona como um sistema de referências, dando sentido às condutas e possibilitando a compreensão da realidade 
social. Por sua vez, este sistema é objeto de regulações por parte dos meta-sistemas simbólicos (Doise, 1993).

Em suas múltiplas formas de manifestação, a violência deve ser compreendida sempre como um fenômeno social (Campos, Torres \& Guimarães, 2004; Moser, 1991; Velho, 2000). Ela existe num determinado contexto e se efetiva na relação com o outro. Trata-se de uma "interação" entre indivíduos situados em uma dada estrutura social, ocupando papéis sociais e orientados por valores que definem e modelam as possibilidades desta interação. Daí parte a perspectiva de análise da violência enquanto dado cultural e societário, cujas manifestações variam de acordo com o contexto sociocultural e são dotadas de valores complexos e diversificados. Apesar das dificuldades de delimitação conceitual, parece consensual entre os pesquisadores (Michaud, 2001; Velho, 2000; Wierviorka, 1997) a concepção de violência enquanto fenômeno multifacetado que assume formas e sentidos variados, em acordo com o momento histórico e a cultura em que ele é produzido.

Em uma perspectiva para além do dano causado, seja ele intencional ou não, está a concepção de violência que remete a um excesso, a um abuso, a uma desmesura e que, portanto, faz referência a uma norma (Tavares dos Santos, 1999, 2004). Nesse sentido, o uso da força torna-se violência "quando ultrapassa um limite ou perturba acordos tácitos e regras que ordenam relações, adquirindo carga negativa ou maléfica" (Zaluar, 1999, p. 8). A noção de "norma social", aqui entendida a partir de Dubois (1994), diz respeito a uma regra ou prescrição da conduta ou do julgamento perceptivo que se caracteriza por ser coletivo, socialmente apreendido e referente a uma atribuição de valor, amparada em uma utilidade social. Enfim, podemos sintetizar em termos de prescrição da conduta, que se exprime em termos de ser "bem visto" ou "mal visto" socialmente.

Em suas reflexões, Tavares dos Santos (2004) busca compreender a violência presente nos diferentes conjuntos relacionais, tomando-a como "um ato de excesso, qualitativamente distinto, que se verifica no exercício de cada relação de poder presente nas relações sociais” (p. 8). Para este autor, a violência não se encontra necessariamente articulada ao uso de instrumentos de força bruta e não há uma fronteira que desassocie a violência física, que é imposta pelo excesso de força corporal ou armada, e a violência simbólica, que exclui e domina por meio da linguagem. Desse modo considera a violência

... como um dispositivo de excesso de poder, uma prática disciplinar que produz um dano social, atuando em um diagrama espaço-temporal, a qual se instaura com uma justificativa racional, desde a prescrição de estigmas até a exclusão, efetiva ou simbólica. Essa relação de excesso de poder configura, entretanto, uma relação social inegociável porque atinge, no limite, a condição de sobrevivência, material ou simbólica, daqueles que são atingidos pelo agente da violência (Tavares dos Santos et al., 1998, citado por Zaluar \& Leal, 2001, p. 148).

A noção de violência cobre, portanto, uma vasta gama de eventos e fenômenos no qual o ato violento é a expressão da imposição das necessidades, expectativas e vontades de um ator social sobre as necessidades, expectativas e vontades de outro ator. Nesse sentido, diversos autores ${ }^{1}$ reconhecem a violência como a expressão de um conflito no interior de uma dinâmica de poder.

Na perspectiva assumida pelos estudos atuais no Brasil, um ponto que tem merecido destaque diz respeito à tendência de banalização da violência (Campos, Torres \& Guimarães, 2004; Dimenstein, 1995; Velho, 2000; Zaluar, 2000). Com a atual mudança cultural e as transformações do sistema de valores e das relações sociais, observa-se que as tensões sociais que anteriormente apresentavam desfechos onde tendiam a predominar acordos e negociações, atualmente encontram na violência física ou verbal uma tendência predominante. Nota-se assim uma disposição cultural de se considerar fenômenos de violência explícita (atos agressivos) como sendo, além de freqüentes, "comuns", "naturais", "corriqueiros", "banais", destituindo a violência do lugar da excepcionalidade, para tornar-se uma marca do cotidiano.

$\mathrm{O}$ que caracteriza fundamentalmente a noção de banalização da violência é a legitimação do uso da agressão (física ou simbólica) como forma de regulação/resolução de conflitos de interesses, seja entre pessoas ou grupos. Um reflexo dessa disposição pode ser observado tanto nos jornais televisivos, que mostram assassinatos e brutalidades cada vez mais "motivados" por razões consideradas, do ponto de vista jurídico e social, "fúteis", ou seja, banais e que não mais chocam os telespectadores, como também nos discursos do cotidiano em que agressões consideradas "leves" não são caracterizadas como violências.

Essa percepção denuncia uma outra face da banalização da violência. Trata-se de uma tendência verificada principalmente em estudos com adolescentes (Campos \& Guimarães, 2003), em que o reconhecimento da violência acontece somente nas situações marcadas pela existência da agressão física. Neste contexto ocorre uma vinculação da noção ou representação da violência ao ato agressivo e, prioritariamente, ao ato agressivo resultante em morte.

Outro ponto que merece destaque diz respeito ao grande envolvimento de jovens em contextos e episódios de violência, tanto como autores, quanto como vítimas. Ao que parece, a associação entre juventude (especificamente o período da adolescência) e violência é uma inquietação presente na maioria das sociedades, sejam elas portadoras de elevados índices de desenvolvimento humano, condições e qualidade de vida, ou não. Nota-se uma tendência da opinião pública e do senso comum em relacionar adolescência e violência (principalmente a criminalidade) tão forte quanto à tendência em associar pobreza e violência.

Em um estudo realizado pelo Núcleo de Estudos da Violência da Universidade de São Paulo (NEV/USP), Adorno, Bordini e Lima (1999) buscaram verificar se o aparente crescimento do envolvimento de jovens com a violência é verdadeiro ou se apenas tem acompanhado a dinâmica da

\footnotetext{
1 Tavares dos Santos (1999, 2004), Sawaia (2004), Velho (2000), Wierviorka (1997), Zaluar e Leal (2001), entre outros.
} 
violência em geral na sociedade; constataram sensíveis alterações na presença e participação dos adolescentes no movimento de criminalidade urbana em São Paulo, ao longo dos anos. Segundo os dados levantados, houve tanto um crescimento da participação de adolescentes em crimes violentos (comparativamente à participação da população em geral), como também um aumento da vitimização destes jovens. Além disso, alterou-se também uma outra dimensão da violência relacionada aos jovens: os atos violentos hoje são mais letais. Uma extensa proporção desses atos resulta em grave ofensa ou morte. Segundo os autores citados acima, o aumento da letalidade da violência juvenil deve-se ao aumento do uso de armas em desfechos violentos e ao crescimento do crime organizado nas grandes metrópoles. Afirmam, ainda, que essas alterações estão acontecendo não somente na cidade de São Paulo, mas podem ser percebidas como uma tendência geral da sociedade brasileira.

Estudos recentes (Abramovay \& Rua, 2002; Campos \& Guimarães, 2003; Campos, Torres \& Guimarães, 2004; Oliveira \& Campos, 2003) tendo como foco central a representação social da violência na escola, fornecem-nos importantes elementos para a compreensão do envolvimento e percepção dos adolescentes acerca da violência. No quadro de investigações realizadas neste contexto, a violência surge como fenômeno inscrito nas experiências de vida e presentes no cotidiano da escola. A grande proximidade que os adolescentes experimentam desta realidade encontra expressão no discurso detalhado sobre episódios de violência física, uso de armas, influência de gangues e drogas, falta de segurança e atuações policiais violentas.

Em uma ampla pesquisa realizada por Abramovay, Waiselfisz, Andrade e Rua (2004) nas cidades da periferia de Brasília, constatou-se que a gangue é um espaço alternativo para os jovens, constituindo-se em uma esfera de relações em que eles são levados em conta, respeitados e protegidos. Para esses jovens, pertencer a uma gangue é mais do que passar o tempo, é a busca de um lugar, de uma posição, é estar inserido num jogo de rivalidades, é a procura de uma identidade social no âmbito da cultura. A gangue apresenta-se, portanto, como uma forma de socialização de jovens que se sentem socialmente excluídos e que buscam formas alternativas de inclusão.

A violência ocupa um lugar de destaque nas gangues e grupos de jovens. Segundo dados da pesquisa citada, a violência é percebida como algo comum e naturalizada, como "uma fatalidade que acontece porque tem que acontecer" (Abramovay et al., 2004, p. 174). Assim, a violência apresenta um caráter instrumental, sendo, portanto, destituída de valoração absoluta, podendo ser válida ou não dependendo da motivação, do objetivo, do contexto, contra quem é dirigida etc. Nesse sentido, torna-se válida, por exemplo, em resposta às provocações, em casos em que é necessário “impor moral”, e como defesa a agressões, humilhações, reação a assaltos e roubos. Além disso, as gangues fazem uso da violência quando entram em conflito entre si. Dentre os principais motivos para esse tipo de ocorrência está a disputa pelo poder territorial, onde o desrespeito à demarca- ção das áreas de atuação pode significar uma provocação e o início de um conflito.

Nesse sentido, a Teoria das Representações Sociais ([TRS], Abric, 1998; Jodelet, 2001; Moscovici, 1994, 2003) apresenta-se como uma importante linha teórica situada em uma "posição mista na encruzilhada de uma série de conceitos sociológicos e conceitos psicológicos” (Moscovici, 1994, p. 41), que implica o estabelecimento de relação entre processos dinâmicos sociais e psíquicos.

As representações sociais atuam como sistemas complexos sempre ativados e em ação na vida social. Elas interferem em processos variados, participando como guia na elaboração da realidade, orientando e organizando as condutas e as comunicações sociais. Na concepção de Abric (1998), a representação social (RS) pode ser considerada como "uma visão funcional do mundo que, por sua vez, permite ao indivíduo e ao grupo dar um sentido às suas condutas e compreender a realidade através de seu próprio sistema de referências; permitindo assim ao indivíduo se adaptar e encontrar um lugar nessa realidade” (p. 28).

A partir da perspectiva da TRS, a violência, enquanto fenômeno cultural, é objeto social que suscita representações as quais intervêm em uma dada realidade social. A representação social da violência não deve, portanto, ser tomada isoladamente, e sim analisada em sua relação direta com as comunicações e a pragmática, uma vez que ela está em íntima relação com as práticas do cotidiano.

O presente trabalho teve como objetivo compreender o fenômeno da violência a partir do ponto de vista dos adolescentes, do modo como eles concebem e representam os processos violentos que a sociedade organiza e no qual estão intimamente envolvidos, e como eles organizam suas práticas sociais a partir desses "saberes". A partir de estudos recentes" ${ }^{2}$ sobre a representação social da violência em adolescentes e as manifestações da violência associadas à escola, este trabalho buscou, especificamente, aplicar uma abordagem posicional do estudo das representações, explorando o campo consensual e identificando alguns elementos que podem estar atuando como orientadores e justificadores da ação violenta.

\section{Método}

Participaram deste estudo dez adolescentes, sendo cinco de sexo feminino e cinco de sexo masculino, com idades entre 16 e 18 anos, estudantes do ensino médio de escolas públicas de Goiânia. Os sujeitos foram abordados aleatoriamente no ambiente escolar e convidados a participar espontaneamente da pesquisa. A média de idade dos adolescentes participantes da pesquisa era de 17 anos para os sujeitos de sexo feminino, e de 16,8 anos para os sujeitos de sexo masculino. Foram escolhidas duas escolas entre cinco apontadas pelo departamento de inspeção escolar da Subsecretaria Metropolitana de Educação como sendo as mais violentas da cidade, a partir da quantidade de incidentes

\footnotetext{
2 Abramovay e Rua (2002), Almeida e Pulino (2000), Almeida, Ribeiro e Campos (2001), Campos, Torres e Guimarães (2004), Galinkin e Almeida (2005), Magaganin e Almeida (2000), Menandro, Trindade e Almeida (2005).
} 
registrados e relatórios de visitas. Assim, duas escolas foram sorteadas e realizaram-se cinco entrevistas em cada uma das escolas, ambas de regiões periféricas da cidade.

Para obtenção dos dados foram realizadas entrevistas semi-diretivas, caracterizadas como entrevistas episódicas (Flick, 2002), tendo como eixo temático central a violência. A entrevista episódica combina em sua estrutura convites para narrar acontecimentos concretos da experiência pessoal com perguntas gerais que busquem respostas mais amplas, numa tentativa de acessar o conhecimento adquirido pelo sujeito a partir da própria experiência e o conhecimento geral (não concreto, ligado à memória semântica). As entrevistas foram gravadas, transcritas e posteriormente tratadas como discursos.

Neste trabalho retomamos a abordagem teórica proposta por W. Doise. Conhecida como abordagem das "tomadas de posição" ou dos princípios organizadores das tomadas de posição; abordagem multivariada das diferenças individuais; ou ainda, de um modo mais genérico, como "psicologia societal" (Doise, 2002). Nesta abordagem a noção de consenso é entendida como partilha de pontos de referência, "tomadas de posição" que exprimem, tanto estatística quanto conceitualmente, a diferença. Assim, pode-se pensar que o "sistema representacional" constitui-se em ponto de referência comum, portanto, organizador de um consenso que permite diferentes posicionamentos. As grandes representações ou as "famílias de representações sociais", como prefere Moscovici (2003), constituem uma parte do chamado metassistema social. A rigor, as representações sociais de ordem mais ampla (ou "societal") constituem a principal fronteira entre o metassistema social e os sistemas cognitivos dos indivíduos; enquanto as representações de menor amplitude podem ser tratadas como um "sistema cognitivo de um grupo, acerca de um objeto social”. O estudo das grandes representações, na abordagem das "tomadas de posição”, deve então seguir dois princípios, pelo menos:

1. Os estudos das RS devem levar em conta as diferenças interindividuais.

2. A organização do campo de uma representação não se reduz a um trabalho de categorização dos elementos, mas se funda também sobre o posicionamento dos sujeitos em face de uma ou mais dimensões sociais.

Justamente do ponto de vista empírico e sob a perspectiva daqueles que desejam e/ou devem intervir sobre a realidade social, quando estudamos um grupo social concreto e específico (seja com objetivos analíticos ou de ação), devemos nos interessar pela parte consensual da representação, visto que é ela que define a identidade do grupo. Neste sentido, o software Analyse Lexicale par Contexte d'un Ensemble de Segments de Texte (ALCESTE) funciona como um auxiliar informatizado que faz aglutinar frases (trechos do discurso), aparentemente diferentes em seu enunciado, mas próximas em uma relação de significado. O ALCESTE coloca em evidência aglomerados (mundos lexicais) de palavras (palavras-plenas) que têm por referência um mesmo núcleo de sentido.
Assim, as associações (cujo indicador estatístico é o $\div^{2}$ associativo) de palavras dotadas de sentido (portadoras de sentido), que aparecem com frequiência, constituem os chamados "mundos lexicais"; dito de outro modo, o programa ALCESTE identifica agrupamentos de palavras que são associadas pelos sujeitos, compondo as classes, além disso, fornece as palavras "mais associativas", que apresentam um $\div$-2 associativo mais elevado no interior de cada classe. Para se compreender o significado de cada classe o programa fornece ainda "contextos típicos" nos quais aparecem as palavras dotadas de $\div$ mais elevado, como nos exemplos abaixo:

Classe 1: - "Já morreu um outro amigo meu só porque ele estava com a camisa. Deram três tiros na barriga dele. Só porque ele estava com camisa mesmo do Goiás."

"Aí depois juntou um montão de gente só em dois. Aí segurou ele e começou a bater nele. Um montão de gente só batendo em dois. Aí foi e deu um tapa na cabeça dele e ele caiu no chão. O outro viu e saiu correndo e ligou para os outros colegas dele."

Classe 2: - "Aí eu falo: mãe, não vai adiantar nada bater, você tem que sentar, conversar, ver para tentar ver. Se de tudo na conversa que você esta tendo com ele não adiantou aí sim é outra história."

"Conversando né, porque eu creio que violência não leva a nada. A gente resolve mais na conversa, é na conversa. Só que ele não fazia isso, ele não conversava com ela. Muitas pessoas pensam que se for conversar, tentar conversar, isso não vai levar a nada."

Classe 3: - "Com certeza iria acabar. Mas a base disso está no governo, o governo tem que agir. Se o governo pelo menos olharpara esse lado."

"O bairro aqui é ponto de droga inteiro. Esse bar que tem em frente ai é maloca desses traficantes aí tudo. Esse bar aí. Não tem policiamento, não tem nada. É droga, é arma, é tudo ai. Principalmente à noite. O bairro é perigoso. Poderia melhorar, mas dependendo de quais policiais.

Classe 4: - "As pessoas assim, muitas pessoas se sentem superiores a outra ejá começam. Nem conhecem a pessoa e já julga ela pela aparência. Aijá começa a implicar com as outras por bobeira."

"Ai eles matam a pessoa por pequenas coisas. O que eu mais fico sabendo de confusão ou é por causa de briga, de briguinha que não tem nada a ver. Tipo assim, por exemplo, um menino encarar o outro aí já, nossa Deus, já é um motivo aqui nesse colégio."

Classe 5: - "Às vezes ele pega a minha filha e bate nela no meio da rua na hora que ela vem para a escola, eu fico com medo. Nós falamos para ela: é só a senhora vir e registrar queixa, registrar uma queixa."

"Meu pai ia pondo essa coisa na cabeça dele e a minha mãe ficava enchendo a paciência dele. Ai depois ele ficava muito bravo mesmo. Ai ele falava com a minha irmã ela não tomava jeito. Ai meu pai foi ficando com essa raiva dentro dele aí ate hoje ele não gosta mais do Maurílio não."

\section{Classe 6:}

"Ao mesmo tempo ele não vai ter a educação necessária. Ele não vai ter aquela educação, aquela atenção, aquele amor da família realmente. Então ele cresce uma pessoa sem amor, sem estruturação familiar, sem às vezes, até sem informação. Então com isso o camarada fica mais vulnerável a violência." 
"Eu acho que uma pessoa de renda baixa, ganhando um salário. Não têm como sair, ir ao cinema, ir ao shopping, ao clube, festas, eventos desportivos. Mas, essa pessoa na necessidade parte para o crime. Ela vai acostumar. Praticando esse crime ela vai achar fácil. Acho que e isso."

Palavras-plenas e mundos lexicais constituem, para um dado grupo social, uma espécie de estrutura do texto que, por sua vez, refletem a estrutura da representação social do objeto social enfocado (ou no texto ou em um conjunto de entrevistas). Dito de outro modo, a estrutura de um texto, produzido por um grupo de indivíduos acerca de um objeto social, reflete certa "semântica grupal" acerca deste mesmo objeto, ou seja, uma semântica de referência para os vários relatos e sentidos atribuídos pelos indivíduos ao objeto. Assim, face à uma mesma referência semiológica (uma mesma representação do objeto) os sujeitos podem tomar posições variadas. É importante salientar que o ALCESTE não trabalha somente com palavras, mas também identifica os "contextos típicos" em que elas normalmente aparecem juntas, ou seja, ele fornece frases típicas e sujeitos típicos, o que permite uma compreensão qualitativa do significado das classes estabelecidas, bem como do significado do discurso expresso. Deste modo o ALCESTE permite um trabalho análogo à análise de conteúdo, com base em indicadores estatísticos (Kronberger \& Wagner, 2002; Lahlou, 1998; Reinert, 1990).

\section{Resultados}

A partir do tratamento estatístico fornecido pelo ALCESTE, realizou-se uma análise que opera em três níveis, sendo que no contex to do atual trabalho, empregou-se apenas os dois primeiros. No primeiro nível realizou-se a identificação do campo comum (campo consensual) da representação; no segundo nível, identificou-se o posicionamento dos sujeitos ou grupos face aos campos comuns.

\section{$1^{\circ}$ Nível de Análise: Identificação do Campo Comum da Representação Social da Violência}

A análise do corpus total, obtido através das entrevistas, revelou a existência de seis Classes, organizadas em dois blocos. O Quadro I apresenta essas classes e a relação entre elas. A seleção das palavras que compõem as classes foi redigida levando em consideração a freqüência e o percentual de distribuição de cada palavra em cada classe, considerando-se os $\div$ encontrados. O primeiro bloco, constituído pelas Classes 1 e 5, que estão correlacionadas a 0,60, refere-se à violência enquanto fenômeno próximo aos sujeitos, e presente na realidade cotidiana. O segundo bloco, composto pelas Classes 2 e 4 correlacionadas a 0,72 e pelas Classes 3 e 6 correlacionadas a 0,68 , refere-se essencialmente às motivações e mecanismos (individuais e sociais) desencadeadores da violência.

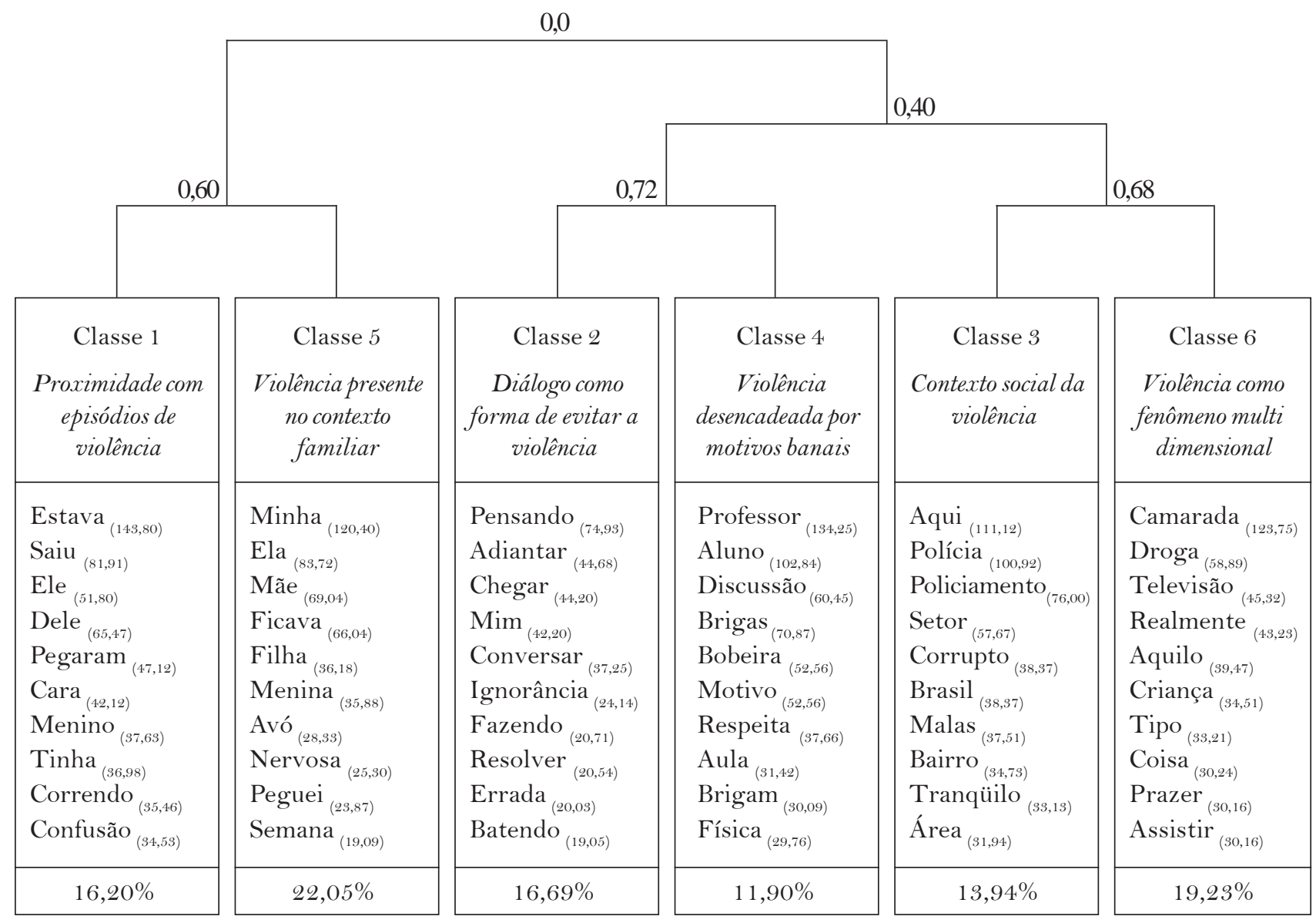

Figura 1. Campo comum da representação social da violência elaborada por adolescentes, organizado em seis Classes. 
Durante as entrevistas foram relatados vários episódios de violência que aconteceram tanto em ambiente escolar como também fora deste. Segundo os entrevistados, os conflitos entre professores e alunos geralmente envolve problemas de comportamento (aluno conversa ou bagunça muito e o professor não aceita) e discussões relacionadas a notas. Já entre os alunos, destacam-se os relatos de incivilidade, troca de olhares e "brincadeiras" tais como piadas e xingamentos, que saem do controle e dão origem a violência.

Com relação às justificativas dos atos violentos que acontecem dentro da escola, percebe-se uma tendência dos sujeitos entrevistados a explicá-los como um momento em que os atores ficaram "nervosos", "agiram no impulso", ou ainda pelo fato de "não saberem conversar" ou não acreditarem no diálogo como forma de resolver conflitos.

Dentre os episódios de violência fora do contexto escolar, merecem destaque os relatos de assaltos à mão armada, rivalidades entre integrantes de gangues (torcidas, bairros ou escolas rivais); violência ligada ao tráfico de drogas e à violência familiar. Nota-se aqui a tendência de perceber a violência principalmente em casos de agressões graves, daí a enorme quantidade de relatos de episódios de violência com desfecho em morte.

Quando solicitados a falar das motivações para o uso de violência, percebe-se uma tendência a buscar na pobreza e nas necessidades financeiras a justificativa para assaltos e roubos. Já nos outros casos de violência as explicações estão ligadas ao descontrole causado pelo álcool ou pelas drogas, a "fraqueza" moral, a falta de estrutura familiar, no prazer em usar a violência, ou ainda, na total ausência de motivadores: "não tem motivos, simplesmente acontece".

\section{Classe 1: Proximidade com os episódios de violência.}

Esta classe concentra a descrição detalhada de episódios de violência física, envolvendo principalmente o uso de armas (revólver e arma branca) e luta corporal. Os sujeitos demonstram grande proximidade com estes episódios que envolvem amigos, vizinhos, colegas ou eles próprios; ao mesmo tempo o discurso sugere certa naturalização desse fenômeno. A organização do discurso em torno dos episódios de violência física indica que estes se encontram incorporados ao cotidiano, fazendo parte da realidade dos jovens entrevistados.

\section{Classe 2: Diálogo como forma de evitar a violência.}

Classe que concentra o discurso de adolescentes mais jovens (16 anos) e destaca o diálogo como forma de evitar a violência. Os sujeitos entrevistados afirmam que muitas pessoas não acreditam que o diálogo seja uma forma eficaz de resolver os conflitos, assim como muitos não têm calma nem paciência para conversar, por isso preferem resolver os problemas através da violência. Nesta classe são apresentados episódios onde as trocas de olhares e as conclusões precipitadas são elementos que propiciam o uso da violência e que, segundo os sujeitos entrevistados, poderiam ser evitados com o diálogo.

\section{Classe 3: Contexto social da violência.}

Nesta classe os sujeitos localizam a violência como estando presente (ou ausente) no bairro, na cidade e no país. Trata-se de um discurso de característica social, que aponta o governo e a polícia como responsáveis pela violência e capazes de atuação contra ela. Nesta classe a polícia é criticada em sua atuação e acusada de ser corrupta e de proteger os bandidos. Nota-se que há diferenças de percepção da violência no que diz respeito à sua localização e proximidade. Alguns sujeitos a localizam como fenômeno próximo e presente na realidade concreta em que vivem; enquanto que outros apontam a existência da violência como um fenômeno distante, localizado "em outros bairros", "em outras escolas".

\section{Classe 4: Violência desencadeada por motivos banais.}

Esta classe destaca um discurso onde as brigas e confusões, na maioria das vezes, apresentam motivações banais. Disputas por um namorado, rivalidade entre times, discordância a respeito de nota, necessidade de auto-afirmação, dentre outros, são apontados como motivos freqüentes para brigas. Nesta classe os sujeitos destacam particularmente o ambiente escolar como palco para a violência motivada por banalidades, envolvendo professores e alunos. Vale destacar que os sujeitos demonstram perceber a banalidade das motivações que envolvem essas brigas e expressam por elas notória reprovação.

\section{Classe 5: Violência presente no contexto familiar.}

Classe que concentra o discurso de adolescentes do sexo feminino a respeito da violência presente dentro do contexto familiar ou tendo a participação de familiares como rede de apoio contra a violência. Em relatos carregados de afeto, os sujeitos entrevistados falam de violência contra a mulher e violência de pais contra filhos, sendo estes tipos de violência muitas vezes presentes dentro do próprio contex to familiar do sujeito. Nesta classe também, membros da família são apontados como pertencentes a uma rede de proteção contra a violência e o sentimento de insegurança.

Classe 6: Violência como fenômeno multidimensional: drogas, miséria, personalidade, criação familiar etc.

Esta classe concentra o discurso de adolescentes mais velhos (18 anos) do sexo masculino, a respeito das possíveis causas da violência. Os sujeitos entrevistados apontam a miséria, a fome, as drogas, a criação familiar, a personalidade, dentre outros como elementos que levam as pessoas a usarem a violência. Nesta classe o papel da estrutura e educação familiar é destacado pelos sujeitos. Os adolescentes entrevistados sugerem que, uma vez usada a violência como forma de obtenção de vantagens, esse meio torna-se fácil, banal, comum, e dificilmente é abandonado. 


\section{$2^{\circ}$ Nível de Análise: Posição dos Sujeitos Face ao Campo Comum das Representações Sociais}

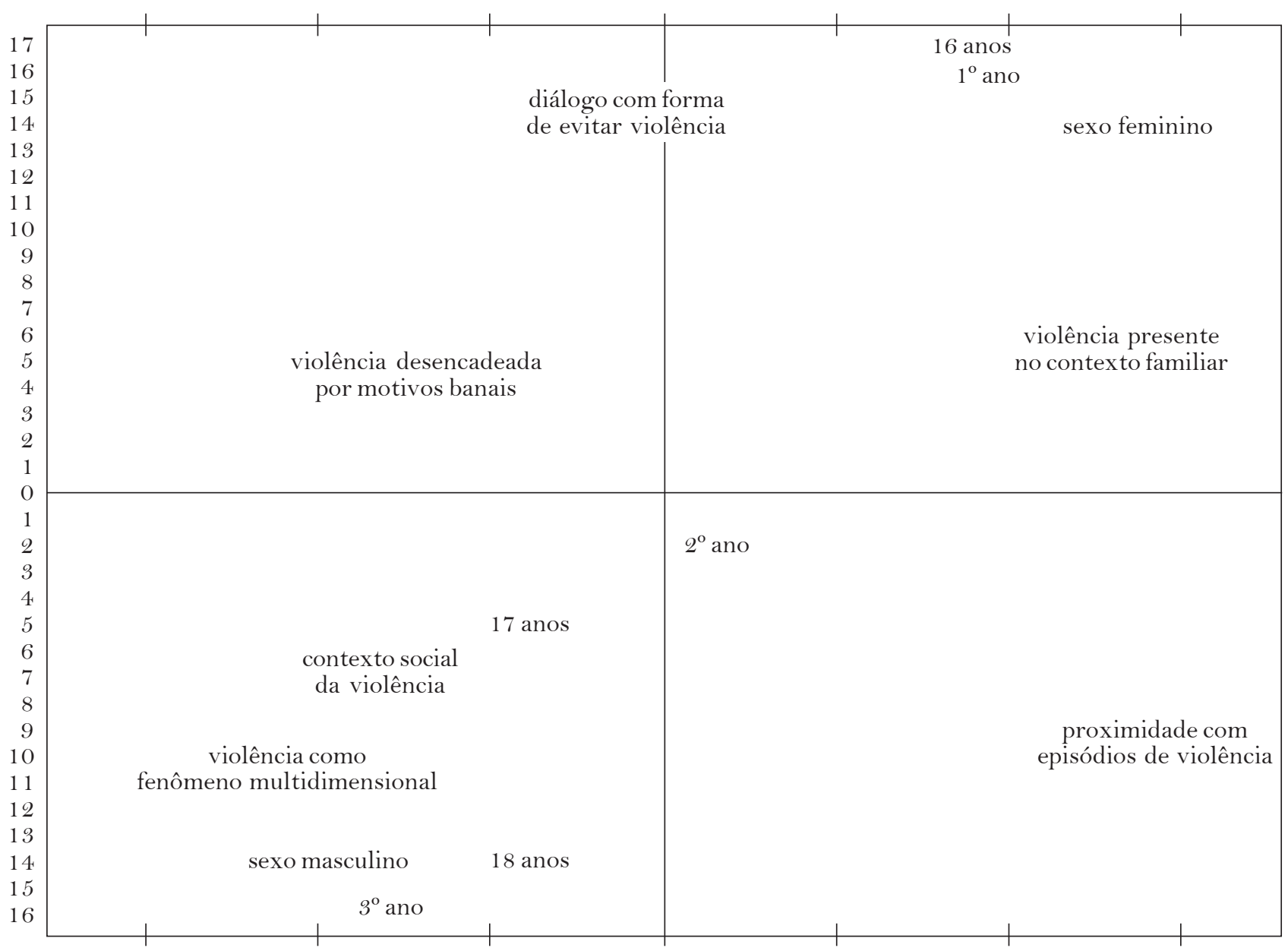

Figura 2. Plano Fatorial com a projeção das classes e variáveis estudadas.

A Análise Fatorial de Correspondência permite a visualização das diferenças grupais no plano fatorial, possibilitando uma complementação das informações de tipicidade já apontadas na Classificação Hierárquica Descendente, conforme a distribuição das classes. No procedimento realizado através do ALCESTE, a análise fatorial toma como base as palavras e seus $\dot{\circ}^{2}$ associativos ${ }^{3}$. Assim, a Figura 2 apresenta o Plano Fatorial contendo a projeção das variáveis e das seis classes examinadas anteriormente. Em razão da compreensibilidade dos resultados as palavras mais "freqüentes" (de maior Qui-quadrado associativo) de cada classe não são apresentadas no plano fatorial. A distribuição não aleatória destes elementos em diversas zonas do Plano Fatorial possibilita a percepção de duas grandes dimensões acerca da violência.

\footnotetext{
${ }^{3}$ A Classificação Hierárquica Descendente toma por base as “U.C.E.", unidades de contextos elementares, equivalentes a sentenças (frases) artificiais arbitrariamente recortadas pelo programa, a partir dos quais se calculará os Qui-quadrados das palavras plenas encontradas. No estudo atual, foram analisadas 3.279 palavras diferentes, alocadas em 1.226 u.c.e.. Em seguida a esta distribuição, são associadas às classes identificadas e, depois, as variáveis selecionadas pelo pesquisador para análise. Deste modo a análise é realizada tomando por base as 3.279 palavras e não os 10 sujeitos.
}

A primeira dimensão está relacionada às questões de gênero, onde a representação social da violência apresenta distinções segundo o gênero masculino e feminino. O discurso dos sujeitos do sexo feminino organiza-se em torno de uma concepção de violência como inerente à pessoa e às relações interpessoais. Nesse sentido, as relações familiares e o contex to familiar são apresentados como frequentemente permeados pela violência. As dificuldades de reflexão e diálogo diante dos conflitos existentes nas relações interpessoais são apontadas como elementos que propiciam o uso da violência.

Por outro lado, o discurso dos sujeitos do sexo masculino apresenta uma visão mais social da violência. Trata-se de um discurso que aponta para as causas e condições que favorecem a violência, e que destaca a existência da violência enquanto fenômeno socialmente localizado e determinado. A ineficácia e corrupção da polícia, o descaso do governo, o uso de drogas, a pobreza, o tipo de educação familiar etc., são elementos apontados como estando diretamente relacionados à violência.

Comparando esse discurso ao discurso feminino, nota-se que há uma diferença de foco. Enquanto os sujeitos de sexo feminino têm uma percepção da violência mais ligada às 
microrrelações de poder e aos conflitos interpessoais, o discurso dos sujeitos de sexo masculino destaca as macrorrelações de poder, apresentando uma visão socialmente mais ampla da violência.

Uma segunda dimensão aponta para uma diferenciação da percepção de violência de acordo com a faixa etária dos adolescentes entrevistados. Os adolescentes mais jovens (16 anos) concentram seus discursos acerca da violência localizando-a enquanto fenômeno inerente às relações interpessoais, enquanto que os adolescentes mais velhos (18 anos) apresentam um discurso voltado para uma percepção da violência enquanto fenômeno socialmente estruturado.

Nota-se, portanto, uma proximidade entre os discursos que marcam os sujeitos de sexo feminino e os mais jovens (16 anos), e uma proximidade entre o discurso tipicamente masculino e o discurso de adolescentes mais velhos (18 anos). Vale ressaltar que esta proximidade de discurso não pode ser explicada por um viés de distribuição da amostra, encontrando justificativa em elementos socioculturais que possibilitam aos adolescentes mais velhos estarem voltando seus interesses e atenções mais para o mundo externo que os adolescentes mais jovens.

\section{Considerações Finais}

O conjunto de dados apresentados neste estudo ilustra e reforça tendências já anteriormente apontadas no que diz respeito ao fenômeno da violência, particularmente em sua relação com a juventude: a existência de uma banalização da violência e, como conseqüência disso, a emergência de um discurso onde a violência é reconhecida como tal em situações marcadas pela agressão física.

De modo geral, o discurso demonstra que estes sujeitos situam a violência como uma "fatalidade", "algo que acaba acontecendo", um fenômeno comum, corriqueiro, e comumente desencadeado por motivos banais. Esse tipo de representação faz com que os sujeitos apontem a presença de uma violência generalizada e, ao mesmo tempo, associem-na diretamente à agressão física. Nota-se que há uma consciência de que atualmente os episódios de violência física são desencadeados por motivos irrelevantes e que poderiam ser evitados. Apesar da valoração negativa que envolve a violência, esta, de certa forma, é vista pelos sujeitos como algo "comum", sendo até mesmo "esperada" em certos contextos, como fazendo parte de uma norma social.

Essa visão banalizada e normatizada da violência é denunciada também pela percepção que os adolescentes têm da própria escola. Apesar de as escolas pesquisadas serem reconhecidas pela Subsecretaria Metropolitana de Educação como estando entre as mais violentas de Goiânia, os alunos de modo geral não reconhecem a própria escola como sendo "violenta". Esta visão pode ser sintetizada pela expressão "há violência nas escolas, mas na minha não", comum entre os adolescentes pesquisados.

Vale notar a grande proximidade que os sujeitos experimentam de episódios de violência física, envolvendo principalmente o uso de armas (revólver e arma branca) e a luta corporal. Ao relatarem suas vivências cotidianas, os adolescentes entrevistados apresentam as relações sociais, de modo geral, permeadas pelo conflito e pela violência. Trata-se de modos de interação onde as conflitualidades encontram espaço privilegiado. Esses relatos vão ao encontro com o que Tavares dos Santos $(1999,2004)$ denomina como fenômeno da "violência difusa", ou seja, a existência de um modelo de sociabilidade que perpassa os diferentes contextos de interação social e cujo princípio de organização é o recurso universal á força.

Nesse sentido, Silva (2004) aponta que os padrões de sociabilidade convencionais, reguladas no âmbito do Estado, em determinados contextos e sob certas condições, perdem a validade e são substituídos por um complexo de práticas estruturadas na relação de forças. Ao que parece, o uso da força como princípio de regulação das relações sociais convive com o modelo de sociabilidade regulada pelo Estado (ligado à legalidade e ao controle social). Segundo o autor, não há luta, mas uma convivência de referências e códigos normativos distintos e igualmente legitimados, que implicam a adoção de recursos de ação divergentes segundo o contex to vivido pelo sujeito. Os relatos dos adolescentes entrevistados sugerem uma articulação de suas práticas a essa dupla inserção: como participantes da ordem estatal e paralelamente, da sociabilidade violenta.

Enfim, o conjunto de dados aqui apresentados pretendeu uma tentativa de compreensão da estrutura da representação social da violência elaborada por adolescentes, buscando com isso suscitar reflexões e instigar questionamentos que contribuam para a compreensão do sistema simbólico que atua na gestão desse fenômeno e a identificação dos elementos que atuam como organizadores da ação violenta.

\section{Referências}

Abramovay, M., \& Rua, M. G. (2002) Violência nas escolas. Brasília, DF: UNESCO.

Abramovay, M., Waiselfisz, J. J., Andrade, C. C., \& Rua, M. G. (2004). Gangues, galeras, chegados e rappers: juventude, violência e cidadania nas cidades da periferia de Brasília. Rio de Janeiro, RJ: Garamond.

Abric, J. C. (1998). A abordagem estrutural das representações sociais. In A. S. P. Moreira \& D. C. Oliveira (Eds.), Estudos interdisciplinares de representação social (pp. 27-38). Goiânia, GO: AB Editora.

Adorno, S., Bordini, E. B. T., \& Lima, R. S. (1999). O adolescente e as mudanças na criminalidade urbana. São Paulo em Perspectiva, $13(4), 62-74$.

Almeida, A. M. O., \& Pulino, L. H. C. Z. (2000). Introdução. In A. M. O. Almeida \& L. H. C. Z. Pulino (Eds.), Fórum de combate à violência (pp. 13-18). Brasília, DF: Editora da Universidade de Brasília.

Almeida, A. M. O., Ribeiro, A. S. M., \& Campos, P. H. F. (2001) Bem-estar, maus-tratos e risco: Da violência suposta à violência reconhecida. Estudo: Vida e Saúde, 28(4), 561- 590.

Campos, P. H. F., \& Guimarães, S. P. (2003). Representações de violência na escola: Elementos de gestão simbólica da violência contra adolescentes. In III Jornada Internacional e I Conferência Brasileira sobre Representações Sociais (pp. 2492-2509). Rio de Janeiro, RJ: Editora da Universidade Estadual do Rio de Janeiro. 
Campos, P. H. F., Torres, A. R. R., \& Guimarães, S. P. (2004). Sistemas de representação e mediação simbólica da violência na escola. Educação e Cultura Contemporânea, 1(2), 109-132.

Dimenstein, G. (1995). O cidadão de papel. São Paulo, SP: Ática.

Doise, W. (1993). Logiques sociales dans le raisonnement. Lausanne, France: Délachaux et Niestlé.

Doise, W. (2002). Da Psicologia Social à Psicologia Societal. Psicologia Teoria e Pesquisa, 18(1), 27-35.

Dubois, N. (1994). La norme d'internalité et le liberalisme. Grenoble, France: Presses Universitaires de Grenoble.

Flick, U. (2002). Entrevista episódica. In M. W. Bauer \& G. Gaskell (Eds.), Pesquisa qualitativa com texto, imagem e som. (pp. 114136). Petrópolis, RJ: Vozes.

Galinkin, A. L., \& Almeida, A. M. O. (2005). Representações sociais da violência entre adolescentes e professores de classe média. In L. R. de Castro \& J. Correa (Eds.), Juventude contemporânea: Perspectivas internacionais em saúde, educação $e$ cidadania (pp. 233-252). Rio de Janeiro, RJ: Nau.

Jodelet, D. (2001). Representações sociais: Um domínio em expansão. In D. Jodelet (Ed.), As representações sociais (pp. 1944). Rio de Janeiro, RJ: Editora da Universidade Estadual do Rio de Janeiro.

Kronberger, N., \& Wagner, W. (2002). Palavras-chaves em contexto: Análise estatística de textos. In M. W. Bauer \& G. Gaskell (Ed.), Pesquisa qualitativa com texto, imagem e som (pp. 416-441). Petrópolis, RJ: Vozes.

Lahlou, S. (1998). Penser manger. Paris: PUF.

Magaganin, A. T., \& Almeida, A. M. O. (2000). Violência contra a infância e a adolescência. In A. M. O. Almeida \& L. H. C. Z. Pulino (Eds.), Fórum de combate à violência. (pp. 19-30). Brasília, DF: Editora da Universidade de Brasília.

Menandro, M. C., Trindade, Z. A., \& Almeida, A. M. O. (2005). Representações sociais da adolescência/juventude a partir de textos jornalísticos (1968-1974 e 1996-2002). Arquivos Brasileiros de Psicologia Aplicada, 55(1), 1-13.

Michaud, Y. (2001). A violência. São Paulo, SP: Ática.

Moscovici, S. (1994). A representação social da Psicanálise. Rio de Janeiro, RJ: Jorge Zahar.

Moscovici, S. (2003). Representações sociais: Investigações em Psicologia Social. Petrópolis, RJ: Vozes.

Moser, G. (1991). A agressão. São Paulo, SP: Ática.
Oliveira, J. P., \& Campos, P. H. F. (2003). Representação social da violência na escola em alunos e familiares. In III Jornada Internacional e I Conferência Brasileira de Representações Sociais (pp. 1190-1208). Rio de Janeiro, RJ: Editora da Universidade Estadual do Rio de Janeiro.

Pinheiro, P. S., \& Almeida, G. A. (2003). Violência urbana. São Paulo, SP: Publifolha.

Reinert, M. (1990). Une methodologie d'analyse des données textuelles et une application. Bulletin de Sociologie, 26, 24-54.

Sawaia, B. B. (2004). Uma análise da violência pela filosofia da alegria: Paradoxo, alienação ou otimismo ontológico. In L. Souza \& Z. A. Trindade (Eds.), Violência e exclusão: Convivendo com paradoxos (pp. 21-42). São Paulo, SP: Casa do Psicólogo.

Silva, L. A. M. (2004). Sociabilidade violenta: Por uma interpretação da criminalidade contemporânea no Brasil urbano. Sociedade e Estado, 19(3), 53-84.

Tavares dos Santos, J. V. (1999). Novos processos sociais globais e violência. São Paulo em Perspectiva, 13(3), 3-17.

Tavares dos Santos, J. V. (2004). Violências e dilemas do controle social nas sociedades da "modernidade tardia". São Paulo em Perspectiva, 18(1), 3-12.

Velho, G. (2000). Violência, reciprocidade e desigualdade: Uma perspectiva antropológica. In G. Velho \& M. Alvito (Eds.), Cidadania e violência (pp.11-25) Rio de Janeiro, RJ: Editora da Universidade Federal do Rio de Janeiro.

Zaluar, A. (1999). Um debate disperso: Violência e crime no Brasil da redemocratização. São Paulo em Perspectiva, 13(3), 3-17.

Zaluar, A. (2000). A globalização do crime e os limites da explicação local. In L. Souza \& Z. A. Trindade (Eds.), Violência e exclusão: Convivendo com paradoxos (pp. 49-69). São Paulo, SP: Casa do Psicólogo.

Zaluar, A., \& Leal, M. C. (2001). Violência extra e intramuros. Revista Brasileira de Ciências Sociais, 16, 145-164.

Wierviorka, M. (1997). O novo paradigma da violência. Tempo Social. Revista de Sociologia da USP, 9(1), 5-41.
Recebido: 10/10/2005 $1^{a}$ revisão: $06 / 03 / 2006$ $2^{a}$ revisão: $14 / 06 / 2006$ Aceite final: 17/08/2006 